Agriculture, Agribusiness and Biotechnology

Vol.59: e16160543, January-December 2016 http://dx.doi.org/10.1590/1678-4324-2016160543 ISSN 1678-4324 Online Edition

AN INTERNATIONAL JOURNAL

\title{
Research on the space environment characteristic and the development of the traditional village in China: Taking Pengzhuang in the northern Jiangsu province as an example
}

\author{
Peng Yao ${ }^{1,2,3^{*}}$. \\ ${ }^{1}$ State Key Laboratory for GeoMechanics and Deep Underground Engineering, China University of Mining and \\ Technology, Xuzhou, China; ${ }^{2}$ Collaborative Innovation Center for Resource Utilization and Ecological Restoration \\ of Old Industrial Base, Xuzhou, China; ${ }^{3} J i a n g S u$ Collaborative Innovation Center for Building Energy Saving and \\ Construction Technology, Xuzhou, China
}

\begin{abstract}
Traditional villages in the northern Jiangsu province have a local character and history unique artistic style, traditional culture and art Jiangsu indispensable part. How to make achieving sustainable and harmonious for development in rural areas, it is a major problem currently in these places. In this paper, field research and theoretical analysis a multidisciplinary approach, the traditional villages of northern Jiangsu space environment features, including location and spatial pattern are elaborated, analyzed the current conditions of rural development. Then taking Pengzhuang Village in the northern Jiangsu as example, discuss the current situation as well as its architectural characteristics of the space environment group and architectural types. Discussing the necessity of architectural features traditional villages in Northern implementation of conservation is proposed as the main ecological environmental protection and rural development policy space. Beautiful traditional village development should be coordinated development of economic and social environment, especially in the process of our socialist new rural construction, village spatial patterns of Jiangsu for basic research has positive practical value and farreaching historical significance.
\end{abstract}

Key words: Traditional villages, Space environment, Characteristic, Ecological, Development

\footnotetext{
*Authors for correspondence: peng8y@163.com
} 
As China's social and economic development, people gradually realized the importance of traditional villages with local characteristics of protection. It brought a lot of impact protection is huge, especially the historic city of Pingyao in Shanxi Province and Suzhou, Zhouzhuang Water protection to the local economy brought remarkable economic and social benefits, set off a research study to protect traditional village a small climax. Currently, on the protection of traditional villages discussion and writings have been used, but have not formed a complete and systematic pattern. Theory of Traditional Villages Conservation in foreign countries, especially in Western countries has been relatively mature. European countries, the careful protection of traditional villages, continued maintenance of valuable historical reconstruction of the demolished building, the structure reinforcement, try to preserve the original appearance. Although China has made experience is worth learning in practice, however, this aspect of the theory of a single major repair of buildings and more. There are great differences with China's national conditions of foreign cultural background, geographical environment, technical measures and so on, some of its theories and methods are not applicable to our country. Meanwhile, the construction of traditional village villages in China's economic construction also plays an important role. If there is a beautiful place characteristics of traditional village, "Beautiful China" will be a lack of content. But local characteristics of the traditional villages construction is not only the economic aspects of the construction, because the traditional villages are not isolated things, it is subject to the natural environment and cultural and ecological effects. Thus, the construction of the traditional villages should be "economic, cultural and ecological" building integrated comprehensive sustainability [1].

Traditional villages in northern Jiangsu has a unique local characteristics and history of art style, carrying a large number of different historical periods, different geographical and cultural information is a valuable resource of intangible cultural heritage, traditional culture and arts Jiangsu indispensable part. Thus, the spatial pattern of the village in Jiangsu do basic investigation has a positive real value, especially in the process of building of a new socialist countryside, the effective protection, in-depth study of traditional villages, it has far-reaching historical significance. This article is based on research priorities in Northern Xuzhou Pengzhuang Village building as an example to explain Pengzhuang Village development status and history, architecture and architectural space environment type, and ecological development strategy proposed in Northern traditional villages.

\section{Traditional village in northern space environment features}

Having a special location

As we all know the city and traffic conditions are an important factor affecting the development of a village area, traditional village, this two conditions is especially important. In addition to the traditional villages in Northern Jiangsu facilitate the external traffic conditions, as well as to facilitate contact with the city. Thus, the entire village gathered from the countryside to the Agricultural Marketing Field cities, but also can be transported from the field of urban goods distribution to local villages. Geographical conditions are villages produce natural basis for development, combined with social and economic fundamental is the decisive factor. Inland river port cities and other cities compared to the most significant difference between Subei that it communicate with the outside world characteristics, which in addition to the rise in Northern villages subject to natural conditions, the most important thing depending on traffic and trade development, in other words, the development and the development of transportation and trade villages, namely, trade is closely related to the rise and fall [2].

From the village of North Jiangsu development process and the natural conditions of the inspection can be found more than a variety of factors affect the process of development in different sizes of these factors play a role, and mutual restraint, offsetting, combine to form a joint force. It is in this together, driven along a winding track toward prosperity.

The village has a local art spatial pattern characteristics

Since the majority of villages in northern Jiangsu has been renovation, village spatial pattern can be characterized by its more distinctive divided into the following three categories: First, the main type of street space, the village streets are traffic roads, 
in recent years of new rural Realignment of these roads are converted into hard concrete road, scale and pleasant street, also planted along many plants, sunlight through the trees, on the ground leaving a mottled shadow, pleasant scenery. Second, the main type of waterfront space, protection and use of existing reservoirs and the surrounding landscape of woods, so it was in the heat of summer, with the feeling of paradise [3]. Third is among the main determinant of housing types, this type of residential areas has a strong privacy and thick walls, villages in Northern architectural features in line with this characteristic. Since there will be no motorized vehicles on residential road, so there is no security risk, it is a good place for exchanges between the neighborhood villagers, where you can take care of the child.

\section{Pengzhuang village overview}

\section{Regional features}

Four seasons, mild climate, abundant rainfall, such climatic conditions are very conducive to the growth of crops, and provide space for the village development in Xuzhou. Now Pengzhuang Village is in the west side of town government, and the east close Nianzhuang town, across Highway 323.The village population is about 3134 people, and arable land area is about 1970 acres, respectively belong to 14 villagers group.

From the Qing Dynasty to before the founding of the type, farming gradually enriched. Currently, agriculture, the main planting garlic, garlic planting in the proportion is quite high. Garlic planting area of $90 \%$ of the total cultivated area. Yield per mu is value of about 4,000 yuan. Beijing-Hangzhou Grand Canal south southeast around Peng Village west of the village, passing through 10 group, irrigated field crops, raising the local population, it is a major Huimin project.

\section{Historical development}

From historical records, Pengzhong has been 400 years of history. Pengzhuang Village, before the liberation, is called Peng Township. In 1957, dismantling and rural, township renamed Pengzhuang Village. Pengzhuang before the Qing Dynasty Village mainly is farming, and the main food is crops.
After the founding to the present, gradually replace industrial agriculture, a local leading industry, mainly in manufacturing hardware tools based, in addition to electrical manufacturing, food processing, plastic products, and more than ten companies. Over the last decade, began to appear in some of the manufacturing-based industries, villages have become larger; the village has pig farm, chicken farm. The annual average output of the labor force of 120 people, the village population basic employment problem resolved on the spot. In 1990, investment in the construction of the National Highway 323 runs through Pengzhuang, convenient transportation. So the village agricultural and industrial products can enter the market quickly, produce benefits, but also reduces the production costs and increase the competitiveness of products. In 2006, in response to the higher call into the "national model village", new rural construction is developing. Village road paving cement road, travel is more convenient.

\section{Pengzhuang village architectural characteristics of the space environment art types}

Building group space environment features Pengzhuang Village group of buildings there are three main forms. The first is the determinant, is a typical village in the form of a group of residential buildings, mainly in the north and northwest of the village. Architectural mostly built in rows, each row of the roadway between four meters wide, each household has a family in front of the possessor of cattle shed, the main building with sloping roof and walls forming a closed courtyard. The second type is scattered, related buildings and mainly in the northeast corner of the southeast corner of the village, dating back to the construction of the nineties. Most of these old residential courtyards from a separate building with adobe masonry roof tile double crest. The third is the "Lake-style", the main buildings of the village to the south and southwest. They are lined around the pond was built. Villagers can enjoy the pleasant pond landscape [4]. 


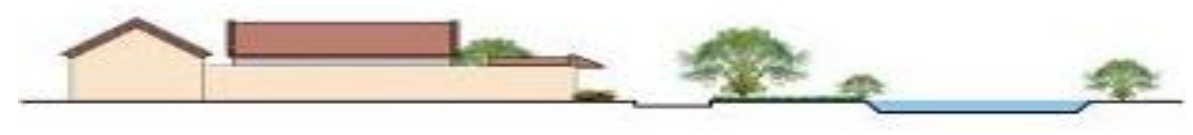

Figure 1: Village characteristic feature space 1

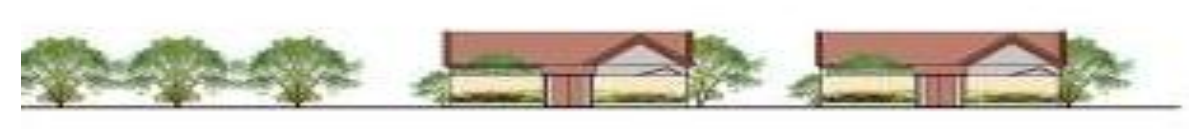

Figure 2: Village characteristic feature space 2

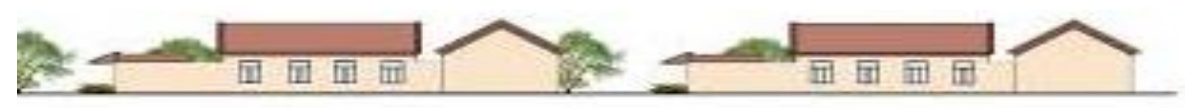

Figure 3: Village characteristic feature space 3

Architecture type

Pengzhuang Village architecture is divided into two main types: the first is the adobe walls as the primary building material, building such a strong sense of texture, heavy sense of history, most of the material to take place. Most of the terrain combined with the local architectural forms, using Weiheshi courtyard. Building roof double crest, simply decorated cornices, brick red tile roof with windows of wood, its people living mostly aged 50 to 60 years of age or older population more. The second is a brick wall as the main building material, in combination with the stone walls at the same time, produce masonry walls. This is generally the bottom wall stone masonry, brick upper part. Some for aesthetic needs, outside the red brick of cement stucco. Its architectural style more than the traditional standard three, each room with three meter three modulo construction, style is relatively simple, its people living mostly middle-aged and a few young people. The main reason people do not want to update the cost of building materials, the purchase price is too high in rural areas who do not want the material on the market[5]. Also part of the traditional brick used for construction, often need to build, it will also heightening construction costs.

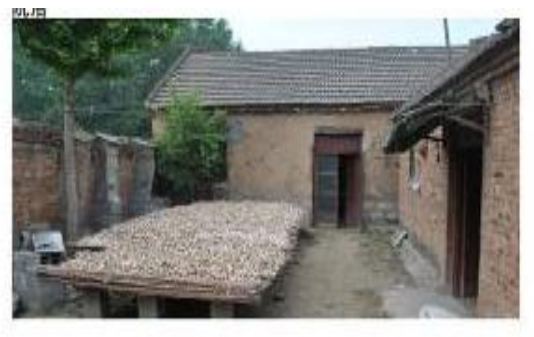

Figure 4: Old typical houses

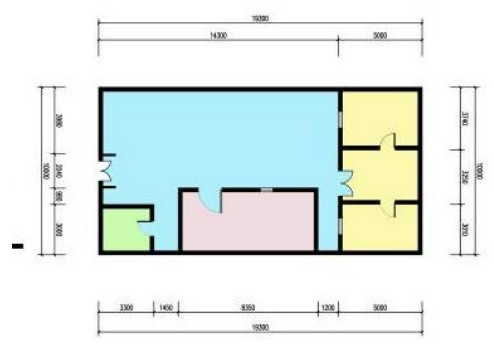

Figure 5: Old typical houses plane 


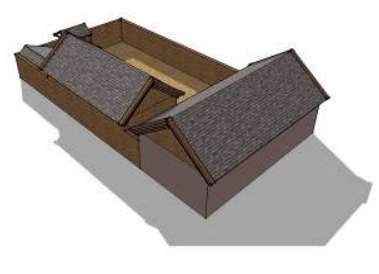

Figure 6: Old typical houses model

\section{Traditional village development strategy}

Protection of traditional village Maintain the integrity of the traditional villages Pay attention to the integrity of the historic village, the protection of historical memory in each period, to prevent the blind shape style specified period [6]. Increased tourism village heritage conservation value, increase tourism and cultural promotion, this could make the sources of income of residents increased visitors to benefit from the tourism. At the same time, to prevent one-sided pursuit of economic value, so that people should be fully aware of the special nature of traditional architectural value, dealing with economic relations and protection, building public participation model, in order to obtain the support of the residents, so that people enter into the development and protection decision related development issues in the past [7]. For example, for conservation planning of Pengzhuang Village on it first from the old village of roadway system and start combing space, focusing on the village center of public life, then "stretched" to the village roadway systems and other living space systems [8].

Typical use of traditional building protection In the main historic buildings, traditional courtyard entrance, try to choose local materials, suspension identity protection, implement supervise protection. According to protection class building, part of the reservation class building, reconstruction class building three types of historic buildings and traditional indoor courtyard facade renovation and repair[9]. Traditional Village repair environmental factors: on the walls constituting village historic features, stone, trees, mountains, water and other elements to fix it. In short, the village resources to deal with integration and utilization, and establish a sound protection mechanism, in particular, focus on the protection overall shape villages; rehabilitation and upgrading of traditional key sites of cultural value. For Pengzhuang Village traditional architectural planning space layout should reflect the characteristics of the countryside and contact landscape planning, control and spatial scales, in a people-oriented principle, to create a pleasant living space.

The establishment of evaluation system Determine the evaluation system, should follow the protection, operational principles, combining traditional architecture with its own characteristics region, the status quo in terms of architectural art, architecture and social conditions, architectural value, the formation evaluation system. In dealing with some tough construction, the overall focus of the measures taken to do it, and in strict compliance with conservation planning coordination area on the traditional style of style, material, color, height and line of sight control requirements, taking into account local traditional design style architectural elements: windows style, flowers form, composition roof, layout, etc[10-11].

The application of ultrasonic wave in historic building protection

There are three analyses of the architecture features on the protection of the historic buildings as results. They mainly include architectural image, materials and technology, architectural color. Many historical buildings were damaged due to improper protection method. A method is to use the Ultrasonic wave in historic building materials detection. Now medical ultrasound has been widely used. If the ultrasound wave application in building protection, people can be better to know internal damage of old building materials. This new method on Ultrasonic wave had practical application in engineering, and had certain reference value. Using the detection of medical Ultrasonic wave to protect old building is a good way.

Traditional village of ecological development strategy

Focus on ecological sustainability in the planning and construction of villages, the unity between man and the natural environment into account. For example, the village green designs combine to form a wind forest. Windbreaks can be set to play the role as soon as possible mitigation, energysaving building sheltered very effective. Try to plant the trees to increase the height and width, so 
the effect is like the wind, while increasing the density of the trees the wind, which can reduce the wind speed [12]. At the same time, protect the natural ecological environment, temperature and humidity play green plants improve air quality effect.

Designed architectural space layout Reasonable space design is in full use of the building to meet the functional requirements of the premise of reasonable construction space separated. Centrally arranged building small footprint, it can fight large green area. Therefore, in the design process, designers should not blindly use of modern design, but to fully understand the regional characteristics. Learn the ecological environment and the local cultural background around the good conduct of the overall architectural design fit with the surrounding environment, and create harmony and unity of effect.

Application of building energy-saving measures Vertical energy-saving measures Using energy-saving vertical wall external insulation is the most common form of insulation in most parts of our country. This external insulation for the maintenance of the inner surface of the structure can maintain a higher temperature. However, due to the influence of external temperature changes, easy to crack the surface layer, so that the construction process requirements are relatively high. Adoption of effective energysaving building materials, efficient use of materials or insulation material is attached to a wall filled walls increase the thermal resistance, avoid outdoor climate affects the indoor temperature [13]. In addition, the emphasis on the use of energy-efficient windows and doors, insulation requirements according to different regions and set up double and single window boxes empty windows.

Transverse energy saving measures

Summer, radiant heat of the sun makes the roof of extreme temperature rises, the impact of indoor life and work. Therefore, the requirements for roofs insulation structure reduce the impact of heat on the roof of the chamber. One approach is to set the roof ventilation air between layers, by the interlayer ventilation, distribute part of the heat; the roof becomes twice the heat transfer to reduce the spread within the roof surface temperature. At the same time, this can create conditions for strengthening indoor ventilation air flow, reducing the warming sun have caused. When the roof is pitched roof, gable vents can be set at a certain number, enabling rapid convection of air inside the ceiling, or set of large curved tiles, the use of air when the ventilation slot board, the infiltration of rainwater between the roof and Vadan excreted roof.

\section{CONCLUSION}

Development of beautiful traditional village should be coordinated development of economy and social environment, and economic and social development of the spatial structure of the traditional villages mainly in two aspects. First: We should not simply copy or restoration of a traditional village, but it should have a long-term vitality. Second: After the economic and social development, the environment and green building should continue to improve, the various plants into the interior area of the building, making the building not only in space, but also in environmental, ecological, showing some kind of elegant and harmonious art atmosphere. At the same time, we want to keep the authenticity of the traditional villages. There is no basis for prohibiting the reconstruction and imitation, to achieve live and work, to take measures to ensure the safety of historic buildings, disaster prevention facilities[14]. In the eco-development strategy, from the building location, orientation zoning, building orientation, building energy-saving design study conducted aspect of building space, the environment and other architectural exterior space, solve the heat in summer, warm in winter and other issues to improve the eco-design effect. Acknowledgements

Supported by a project grant from the Jiangsu university philosophy social science research general project in 2015 , China ( Grand No.2015SJD427) . And this work was supported by JiangSu Collaborative Innovation Center for Building Energy Saving and Construction Technology, China. Village characteristic feature space analysis chart drawn by Cheng Yu-chuang, and typical houses diagram analysis drawn by $\mathrm{Li}$ Ang and Li Biao.

\section{REFERENCES}


1. Chang Qing, Architectural heritage protection and utilization of survival strategy--the design experiment. Tongji university press, Shanghai, China, 2003, (In Chinese).

2.Carmen Salazar-Hernández , Jorge Cervantes , María Jesús Puy-Alquiza , Raúl Miranda: 'Conservation of building materials of historic monuments using a hybrid formulation', Journal of Cultural Heritage , 2015, 16, 185-191.

3. Zhang Qi, He Yaoxuan: 'History and the developmental trend of architecture renewal thought in China', Urban Studies, 2011, 18, 29-30 (In Chinese).

4. Peng Yao: Research on the Protection of Historic Building Features in the Reconstruction of the Old City', Advanced Materials Research, 2013, 726731,3593-3595.

5. Malgorzata Hanzl: 'Information technology as a tool forpublic participation in urban planning:a review of experiments and otentials', Design Studies, 2007,28 , 291-293.

6. Romeu Vicente, Tiago Miguel Ferreira, J.A. Raimundo Mendes da Silva: 'Supporting urban regeneration and building refurbishment. Strategies for building appraisal and inspection of old building stock in city centres', Journal of Cultural Heritage, 2015, $16,1-14$.

7. Li Qirong: 'Urban planning and historic preservation'. Southeast university press, Nanjing, China, 2003, (In Chinese).

8. Peng Yao: 'Studying on Identification of the Historic Building in the Building Legacy Protected', The 2nd International Conference on Multimedia Technology, Hangzhou, 2011, 1258-1259.

9. Daraio C: 'Design of New Materials for Health, Energy and the Environment', Computer Graphics Forum, 2015, 34: XXIII-XXIII.

10.Fan Xiaolin, Miao Kun, Lv Rui: 'Study on the strategy of ancient village protection and development:a case of the linfeng village of jia county in henan province', Huazhong Architecture, 2011,29, 159-160, (In Chinese).

11.Mercuri AM , Montecchi MC, Pellacani G ,Florenzano A, Rattighieri E, Cardarelli A: 'Environment, human impact and the role of trees on the Po plain during the Middle and Recent Bronze Age: Pollen evidence from the local influence of the terramare of Baggiovara and Casinalbo', Review of Palaeobotany and Palynology, 2015, 218: 231-249.

12. Kristian Fabbri: 'Energy incidence of historic building: Leaving no stone unturned', Journal of Cultural Heritage, 2013, 14S , 25-27.

13. Huang Lin-Lin, Ikeda Koichi, Hojo Sachiko: 'Study of the different Cutoff Point of the QEESI Questionnaire as a Screening Tool for Sick Building Syndrome Diagnosis in Taiwan', Journal of Asian
Architecture and Building Engineering, 2014, 13: 507-513.

14. CHEN Hong yu: 'Protection of Architecture Legacy in the Perspective of Sociology', Hundred Schools in Arts, 2011,8:112-113, (In Chinese).

Received: June 15, 2016; Accepted: June24, 2016 